\title{
Research on the Integrated Construction Technology of Granite Ground Crystallization
}

\author{
Shan Zhu ${ }^{1, a}$, Xiao-xu Meng ${ }^{2}$, Hai-ping Wang ${ }^{1}$,Leng-jing Liu ${ }^{2}$ \\ 1 School of Management, Qingdao University of Technology, China \\ ${ }^{2}$ School of Management, Qingdao University of Technology, China
}

Keywords: Granite ground, Pattern slicing, Crystallization, Construction Technology, Seamless treatment.

\begin{abstract}
Granite ground construction quality is directly related to the quality and the grade of the building, which also has great impact on the building. This paper aiming at the quality problems easily occurred in the granite floor construction, putting forward 4 essential integrated technology, namely CAD numerical control pattern slicing technology, Laser theodolite orientation positioning and mapping typography technology, granite ground seamless treatment technology, granite ground crystallization processing and construction technology.Use these four integrated technology, the ground will be more smooth and light, and the methods will be more efficient, environmental and economical. In the end of this paper analyze economic and social benefits combined with detail engineering examples.
\end{abstract}

\section{Introduction}

With the increasing of various large public buildings and high-rise buildings, modern people put forward higher requirements on the public environment and the aesthetic degree of private space. Throughout the various building materials, granite stone material is often used in the wall, ground and other buildings decoration works ${ }^{[1]}$, thanks to its hard texture, beautiful colors, and other characteristics, In recent years, China has gained remarkable progress in stone technology.However, in general speaking, granite ground construction survey is still the weakest link, which will be directly related to the grade and the level of the building.Improper pavement method may produce granite surface hollowing, whickering, seam defects, poor durability, and low flatness; therefore, how to improve the quality of the construction becomes a highly concerned problem in engineering area.

\section{Integrated technology principle analysis}

\subsection{CAD numerical control pattern slicing technology}

Use CAD and CNC numerical control system integration. It can solve problems such as rough patterns section, large stitching seam, high cutting tool cost and low processing efficiency. It can reduce the

${ }^{a}$ Corresponding author : 941818782@qq.com 
number of re-fight splicing errors occur, achieve seamless parquet, and make parquet slicing process efficiency.

\subsection{Laser theodolite orientation positioning and mapping typography technology}

The emitted horizontal and vertical line of the laser theodolite are used as the reference position, to set up system axis control network, to achieve the whole process control of locating and mapping typesetting. This technology can ensure the positioning accuracy and quality, and speed up the construction progress.

\subsection{Granite ground seamless treatment technology}

Make secondary cut slotting, jointing treatment along the original slot on the paved granite ground, tools for the special stone material slitting machine, caulking material with stone color similar environmental quality marble glue. It can reduce the color difference between plates which will completely solve the problem of crack height difference.

\subsection{Granite ground crystallization processing and construction technology}

After filling marble glue, grind on the ground twice and three layered polished. Stone grinding machine make the plate produce physical and chemical effects under the heavy pressure and high temperature, to form a hard layer of crystal. After crystallization treatment, the phenomenon such as cutting mouth and faulting of slab ends disappeared, and the ground will have an effect bright as a mirror.

\section{Integrated key technology construction points}

The ground granite crystallization construction process is : Construction preparation- CADcomputeraided typesetting-CNC numerical control cutting and slicing-Trial assembly, pattern- Edge grindinglaser theodolite orientation, high elastic line and selection-Mapping typography-Trial arrangementlaying - Line snapping - Secondary cutting-Filling-Rough grinding- Fine grinding- Crystallization process- Product protection

\subsection{CAD numerical control pattern slicing}

(1)CAD computer-aided typesetting: make CAD pattern design to granite ground with computer-aided design software, and the $\mathrm{CAD}$ computer pre-typesetting on entire granite ground, to ensure the overall coordination and beautiful ground pattern.

(2)CNC numerical control cutting and slicing: to convert the designed CAD pattern into CNC program, and then send CNC program to CNC digital control water cutter for integrated automatic cutting, automatic water cutter will cut the stone into different sizes and shapes of slices.

(3)Trial assembly, pattern: to trial assemble the cutting parts in a unit, surface smoothness and flatness error of each unit required to be less than $1 \mathrm{~mm}$ in assembly.

(4)Edge grinding: place the splicing panel for $24 \mathrm{~h}$, after the binding agent is drying off, grinding on the horizontal and vertical direction between panels, the grinding process is divided into coarse grinding and fine grinding. 


\subsection{Laser theodolite orientation positioning and mapping typography}

(1)Positioning: using laser theodolite positioning the leveling layer of the ground, strictly control the elevation and flatness of the leveling layer before concrete pouring at the grass-roots level, strengthen the control of bonding layer thickness.

(2)Mapping typography: According to the requirements of drawing size and arrangement, using a laser theodolite infrared responses to laying off $50 \mathrm{~mm}$ baseline (control line)at all the walls and pillars, check the level elevation and pillars deviation, etc. Laying off horizontal and vertical control line to form control mesh.

(3)Trial arrangement: to make arrangement in advance according to the snapping line on the ground, numbering the panel and drawing the layout chart, sit in the right seat in construction.

(4)Laying: check the cumulative error paving every 10 pieces of granite, when error is beyond $5 \mathrm{~mm}$, one should check the deviation of the pay-off with laser, and make adjustment, analyze the causes of deviation, and continue the paving after trial paving is correct.

\subsection{Granite ground seamless treatment}

(1)Clean the filling inside the granite ground seam: use the portable cutting machine to eliminate the solidified filling in the gap preliminarily. Add the cusp outlet on hair dryer to blow the dust inside the seam, and then use a vacuum cleaner to inhale dust in seam completely.

(2)Secondary cutting of the granite ground:

1)Line snapping: using laser theodolite for pay-off straightening in the seam, there needs to line snapping according to seam width correct on the uneven width part, the line is made of fine and high toughness nylon yarn ${ }^{[2]}$.

2)Secondary cutting: use alloy cutting thickness of $2 \mathrm{~mm}$ of special stone material slitting machine to cut and slot along a straight line, to make the gap width difference between the stones to a minimum.

3)Filling: use the dedicated marble adhesive with the same color of the stone and according to the requirements of manufacturer, make the color fully close to the original stone, and use it to fill the new slotted seam.

\subsection{Granite ground crystallization processing and construction}

\section{(1)Rough grinding}

Using stone grinding machine and 50\# granite refurbished piece for the first grinding, grinding area is $2 \mathrm{~m} \times 2 \mathrm{~m}$, granite grinding machine should be push-pull 4-5 times repeatedly in the grinding area. Again, in turn, use 200\#, 500\# granite refurbished piece for second and third rough grinding on granite ground,the grinding area and method are the same as the first grinding.

After the rough grinding, the granite surface snip should be largely disappeared, and presented the fine and smooth feeling, with faint burnish.

(2)Fine grinding

Replace $800 \#, 1500 \#, 2000 \#$ granite refurbished piece in turn on the stone grinding machine, and make comprehensive fine grinding on granite ground with the same method as rough grinding.

At the end of the fine grinding, granite ground should be more smooth, using metering instrument to test the surface gloss, the glossiness should be about 40 to 50 degrees.

(3)Crystallization process

1)Spray the hard agent k-2 evenly on the granite ground, and remove the special crystal processor to conduct detailed uniform grinding, processing area is about $2 \mathrm{~m} \times 2 \mathrm{~m}$. Then spray a small amount of $\mathrm{k}$ 3 light agent, and also be polished until smooth.

2)Repeat the hard, and light processing for 4-5 times, until the brightness measured by light meter is above 80 degrees. Finally use the hard agent k-2 to process once, make the ground has anti-slip performance.

(4)Polishing 
1)Using steel pads to re-polish the crystallized ground, to treat the added hard and light agent missed grinding ground in construction ${ }^{[3]}$. The glossiness of the polished granite ground should be over 85 degrees.

2)After polishing, let it air dried and stood for 10 days. After drying, brush 3 layers of nanoscale stone protective agent, each coating should be uniform; nanoscale stone protective agent can ensure the permeability of the ground.

\subsection{Construction points for attention}

(1)The main technical indicators

The main allowable deviations are shown in table 3-1.

Table3-1 Quality standard of granite surface

\begin{tabular}{cccc}
\hline Serial number & Project & Allowable deviation $(\mathbf{m m})$ & Test method \\
\hline $\mathbf{1}$ & Surface smoothness & 0.5 & Automatic flatness detector \\
$\mathbf{2}$ & Seam's straightness & 0.5 & Infrared laser level \\
$\mathbf{3}$ & Skirting line straightness & 1 & laser level \\
\hline
\end{tabular}

(2)Marble glue completely solidified will have a certain degree of contraction, so the filling should make the marble glue is slightly higher than the level of the stone, in order to ensure the marble glue completely after solidification is slightly higher than that of the stone surface $1 \mathrm{~mm}$, so as not to repeatedly filling ${ }^{[4]}$.

(3)Before rough grinding, make granite surface protective treatment. Under the condition of the ground completely dry, granite ground should be besmear to brush over the protective agent, after 20 $\sim 30 \mathrm{~min}$, use cotton cloth to remove the stone surface of the protective agent to remove the residue. And then brushing second times the protective agent, the curing time is 24 hours, during this time the granite surface shall not encounter water ${ }^{[5]}$.

(4)After each grinding, using a suction machine immediately sucked sewage on the ground to prevent from water stains on the stone material of secondary pollution.

(5)the day before the ground crystallization processing, granite surface should be thoroughly clean and dry, dust and sand should be prevented access to the work area in the crystallization process.

\section{Application Examples}

The four integrated technology has been applied to a project in Tsingtao Economy \& Technology Development Area. This project is refined decorated office building which has twenty-four layers on the ground and two-story underground. The main roof eaves height is 97.8 meters, the total construction area is 34832.32 square meters, and the building area is 24383 square meters on the ground. Foundation design grade is A, and the masonry structure of the construction quality control level is a grade B. The design can be used in 50 years. This project is a large area of ground engineering, which has a high requirement of the granite surface. However, the granite ground construction is difficult, and the construction duration is tight.

The four key technologies can ensure the accuracy of granite parquet floor, save the amount of plate, and eliminate the height difference between the seams, ensuring overall surface flatness and mirror effect. It can also reduce the direct labor cost, speed up the construction progress, and shorten the time limit for a project, which saved the direct cost RMB117300, gaining remarkable economic and social benefits.

The main economic benefit analysis is shown in the table 4-1: 
Table 4-1 Economic benefit analysis table

\begin{tabular}{c|c}
\hline Term & Amount (RMB) \\
\hline Direct labor cost, material cost savings & 76200 \\
Implement cost & -17500 \\
Repair and overhaul cost savings & 58300 \\
Post-maintenance cost savings & 10800 \\
Other funds & -10500 \\
Total savings & 117300 \\
\hline
\end{tabular}

\section{Conclusion}

Compared with general stone pavement technology, the Granite ground crystallization construction four integration technology can make the stone material ground to achieve the overall effect of bright and smooth as a mirror. It is suitable for hospitals, hotels, libraries and other projects with high quality requirements on the granite floor or mirror effect.

These four integrated technology in this paper can ensure accurate positioning when paving, eliminate seams poor, and overcome the uneven plate deflection phenomenon. It can also make construction process without waste water, sewage, and prevent the plate secondary pollution caused by sewage. Due to the elimination of the stone gap, it greatly reduces the construction and delivery of the use of clean labor intensity. Using these four integrated technology, most water can be recycled, and the water used in construction is greatly reduced. Not only this, it can also make no noise during the construction. The use of seamless processing and crystallization technology makes granite ground effectively improve skid resistance and durability, extending the life of the stone. In general, CAD numerical control pattern slicing, laser theodolite orientation positioning and mapping typography, granite ground seamless treatment, granite ground crystallization processing and construction of the four techniques are integrated using, granite ground paving is more beautiful, more precise, and prolongs the service life of the granite stone, and making the whole process more economical, environmental and making less carbon, which has great guidance for improving the construction of granite surface in China.

\section{References}

1. Yan-qing Zhao.A discussion on the construction technology of seamless construction technology of stone floor, [J]. Shaanxi Architecture,2010,08:33-35.

1. Jiu-gang Luo.The hub station's Stone finishes secondary polishing and crystal construction technology [J]. Shanxi Architecture, 2013,16: 95-97.

3. Ren-gui Zhu, Ren-jie Wang, Zheng-de Li.Grinding and polishing marble seamless construction quality control[J].Zhejiang building, 2009,10: 50-52 + 56 .

4. Huai-cheng Zhao.Lhasa railway station engineering ground stone crystal construction technology [J]. Science and technology advisory review, 2007, 24:218-219.

5. Yibo Zhang. Granite stone curtain wall construction technology key points analysis [J]. Journal of henan building, 2015, 110:110-112. 